Bangladesh J. Bot. 40(2): 171-175, 2011 (December)

\title{
EFFECTS OF SOIL WATER DEFICIT ON LEAF NITROGEN, CHLOROPHYLLS AND SPAD CHLOROPHYLL METER READING ON GROWTH STAGES OF SOYBEAN
}

\author{
SHAKIL UdDin AHMED \\ Department of Soil, Water and Environment, University of Dhaka, Dhaka-1000, Bangladesh
}

Key words: Soil water deficit, Leaf nitrogen; Chlorophyll (a+b), Growth stages, Soybean

\begin{abstract}
Soybean leaf Nitrogen $(\mathrm{N})$ status correlated linearly with the amount of chlorophylls and SCMR at flowering stage in response to water deficit levels. In addition, SCMR showed significant positive correlation with chlorophylls at flowering stage. Grain yield significantly correlated to the leaf nitrogen as well as to the chlorophylls and SCMR at flowering stage in response to water deficit levels. These relationships indicated that the water stress decreased leaf nitrogen, chlorophylls and SCMR which in turn caused decreased grain yield of soybean. The results from the study suggest that, flowering stage is the best time for prediction on the adverse effects of water stress on leaf nitrogen assimilation, chlorophylls and SCMR on potential yielding ability of soybean.
\end{abstract}

\section{Introduction}

Drought is a world-wide problem, affecting global crop production and quality seriously, and recent global climate change has made this situation more serious. The great challenge for the future will be the task of increasing food production with less water, particularly in countries with limited water and land resources. Shortage of available water is one of the most significant environmental stresses that cause yield reductions in a wide range of crops including soybean (Boyer 1982). There is a pressing need to improve the agricultural water management of rain-fed soybean production. The effects of water stress on soybean yield appeared to be related to limited availability of photosynthate and nitrogen for translocation to developing seeds (Silvius et al. 1977).

Recent reports indicate a close link among leaf chlorophyll concentration, leaf $\mathrm{N}$ content and crop yield, which makes sense because the majority of leaf $\mathrm{N}$ is contained in chlorophyll molecules (Cartelat et al. 2005). The proportion of leaf $\mathrm{N}$ allocated to the chloroplast amounts to approximately $75 \%$ (Huk et al. 1993). When grown in high irradiance, leaves generally have a ratio of $1.0: 1.4 \mathrm{~mol} \mathrm{~N}$ in ribulose-1, 5-bisphosphate carboxylase/oxygenase (RuBPCO) vs. thylakoid N (Evans 1989). The soil plant analytical development (SPAD) chlorophyll meter reading (SCMR) enables users to quickly and easily measure leaf greenness (by measuring the leaf light-transmittance characteristics) which is affected by leaf chlorophyll content. The usefulness of SPAD chlorophyll meter readings (SCMR) for plant $\mathrm{N}$ assessment is based on the direct proportionality between leaf chlorophyll and leaf $\mathrm{N}$ content (Sheshshayee et al. 2006). Plant water stress can affect the ability of the plant to produce chlorophylls, thus affecting leaf greenness (Sandoval-Villa et al. 2002).

Significant correlations between photosynthesis and leaf $\mathrm{N}$ content have been documented for a large number of species, including soybean (Buttery and Buzzell 1988). A positive correlation between leaf $\mathrm{N}$ or $\mathrm{N}$ fertilization rate and chlorophylls content is well documented for a large number of plant species and has been investigated for rapid $\mathrm{N}$ status determination using SPAD

E-mail: <shakiluddinahmed@yahoo.com>. 
meters in most major crops (Mauromicale et al. 2006). Available information suggested that taking SCMR is easy and quick, does not necessitate destructive sampling, and has been employed to predict Chl content in a large number of plant species, including soybean (Marquard and Tipton 1987).

The present study aimed at selecting the best time of evaluating SCMR at different growth stages for prediction of adverse water stress effects on leaf nitrogen status and chlorophylls in determining potential yielding ability of soybean grain.

\section{Materials and Methods}

This research was conducted in a vinyl house (surrounding sides were open). The soil was clay loam in texture $(0.40 \mathrm{~g} / \mathrm{g}$ sand, $0.27 \mathrm{~g} / \mathrm{g}$ silt and $0.33 \mathrm{~g} / \mathrm{g}$ clay). The bulk density was 1.07 $\left(\mathrm{g} / \mathrm{cm}^{3}\right)$. Soil water content at field capacity $(34.7 \mathrm{kPa})$ was $0.516 \mathrm{~m}^{3} / \mathrm{m}^{3}$ and wilting point (185kPa) was $0.296 \mathrm{~m}^{3} / \mathrm{m}^{3}$. Therefore, the total available water (TAW) was $0.220 \mathrm{~m}^{3} / \mathrm{m}^{3}$.

Five water deficit (D) treatments viz. $\mathrm{D}_{1}(0-20 \%), \mathrm{D}_{2}(20-40 \%), \mathrm{D}_{3}(40-60 \%), \mathrm{D}_{4}(60-$ $80 \%)$ and $\mathrm{D}_{5}(80-100 \%)$ of total available water (TAW) were arranged in a completely randomized block design with 12 replications. The TAW is defined as the water content between field capacity $\left(\theta_{\mathrm{FC}}\right)$ and permanent wilting point $\left(\theta_{\mathrm{PWP}}\right)$. The water deficit level of $\mathrm{D}_{2}(20-40 \%)$, for example, meant that the available water deficit was maintained between 20 and $40 \%$ of TAW throughout the growing season. When the maximum allowable depletion of available water came close to $40 \%$ of TAW, water was applied to restore the available water to the deficit level of $20 \%$ of TAW.

Plastic pots (10 liters volume and $23.8 \mathrm{~cm}$ diameter) with no drainage holes were filled with $7 \mathrm{~kg}$ air-dried soil. Then five soybean seeds [Glycine max (L.) Merrill] were sown in each pot. Prior to planting, uniform water was applied to all the pots to bring them to field capacity $\left(\theta_{\mathrm{FC}}\right)$ for uniform germination. The soil moisture for all pots was maintained at field capacity $\left(\theta_{\mathrm{FC}}\right)$ until 14 days after sowing (DAS) and then the deficit irrigation treatments were initiated. The irrigated period of soybean was 20 weeks from June 16 to November 3 . The plants were thinned to one per pot at the 2- to 3-leaf-stage. Three replicate pots of each water deficit (D) level were sampled at 49 DAS (development stage), 77 DAS (flowering stage), 105 DAS (seed growth stage) and 140 DAS (maturity stage) during the experiment. Three plants per treatment were used for final yield analyses.

From each of the water deficit (D) treatments, 3 terminal leaflets of mature, fully irradiated leaves in the top quarter of the canopy were randomly selected according to Fritschi and Ray (2007) within the different growth stages. The leaves were cut at the base of the petiole, placed in plastic zip-loc bags which were then inserted into manila envelopes, and placed on ice. Leaflets were kept in the dark and transported to the laboratory for processing. One leaf disk $\left(1 \mathrm{~cm}^{2}\right)$ was excised from the lower half of each of the three terminal leaflets and immediately placed into opaque vials containing $12 \mathrm{ml}$ of $96 \%$ ethanol for Chl extraction (Lichtenthaler and Wellburn 1981). On each leaflet, 3 SPAD meter (Minolta 502) readings (SCMR) taken near the spot of leaf disk excision were averaged and recorded. Once the SPAD meter readings were obtained, leaflets were combined, dried to constant mass at $65{ }^{\circ} \mathrm{C}$, and ground to a fine powder using a sample mill with a 1-mm screen. The leaf $\mathrm{N}$ status was determined with an automatic high sensitive NC analyzer (Sumigraph NC 95A, Shimadzu Co. Ltd., Japan).

Leaf disks and SPAD meter readings were taken in parallel from a minimum of ten leaves starting at the tip of a shoot and moving basipetally along the same shoot. SPAD meter readings (SCMR) were conducted on the same leaves directly next to, and immediately after, leaf disks had been excised for chlorophylls. 


\section{Results and Discussion}

Good correlation between chlorophylls and SCMR was found for flowering stage $\left(\mathrm{R}^{2}=\right.$ 0.9164, $\mathrm{p}<0.01$ ) but a weaker correlations was observed for other growth stages (Fig. 1 ). The relationships between chlorophylls and SPAD meter readings differed among the different growth stages in response to different water deficit levels.

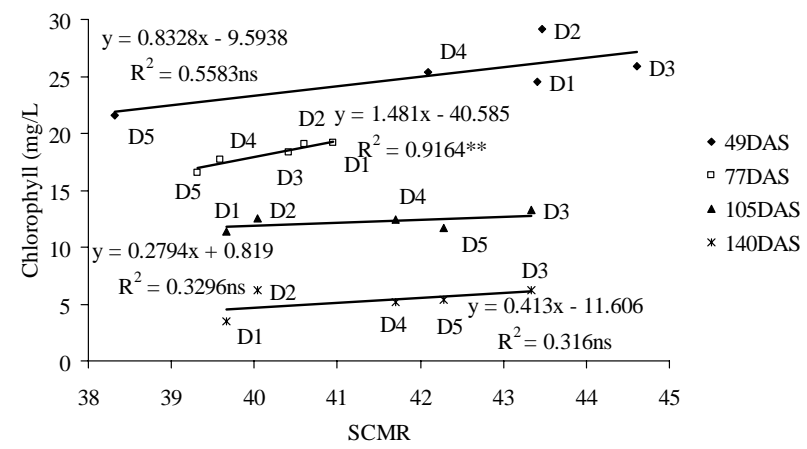

Fig. 1. Effects of water stress on the relationship between SCMR and chlorophylls at different growth stages of soybean. ns: non significant and ${ }^{* *}$ significant at $\mathrm{p}<0.01$.

While the correlations with leaf $\mathrm{N}$ content were significant for both chlorophylls and SCMR $\left(\mathrm{R}^{2}=0.9796, \mathrm{p}<0.01\right.$, Fig. 2(A); $\mathrm{R}^{2}=0.8909, \mathrm{p}<0.05$, Fig. 2(B)) at the flowering stage, non significant correlation was observed for other growth stages under different water deficit levels. Ommen et al. (1999) reported that there was a close relationship between the SCMR and total chlorophyll concentration (obtained from leaf extracts) for wheat under water stress.
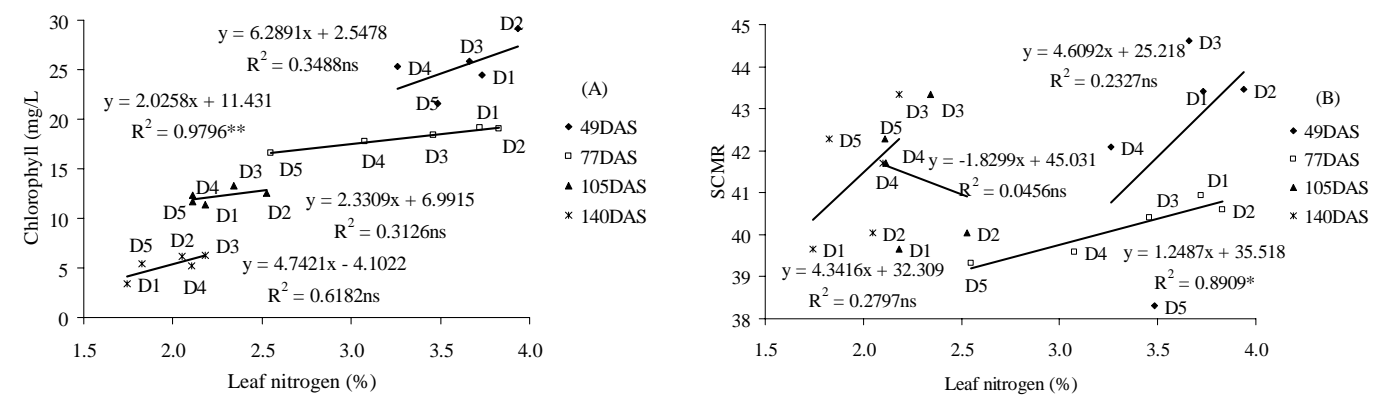

Fig. 2. Chlorophylls (A) and SCMR (B) at different growth stages of soybean against leaf nitrogen under water deficit levels. ns $=$ non significant, ${ }^{*}$ significant at $\mathrm{p}<0.05$, and ${ }^{* *}$ significant at $\mathrm{p}<0.01$.

The grain yield of soybean significantly decreased with the increase of water deficit levels as well as with the decrease of leaf N, chlorophylls, and SCMR (Figs 3(A-C)). It was found from the study that the grain yield numerically lowered by $1,11,21$ and $47 \%$ in $D_{2}, D_{3}, D_{4}$ and $D_{5}$ water deficit levels, respectively, as compared to the $\mathrm{D}_{1}$ (full irrigation). These results indicated that the reduction in crop water requirement by water stress caused the decrease of soil water uptake with soluble nutrients and consequently the decrease of soybean grain yield through the reduction in photosynthesis. 
The soybean grain yield significantly correlated with leaf $\mathrm{N}$ status $\left(\mathrm{R}^{2}=0.9731, \mathrm{p}<0.01\right.$, Fig. $3(A)$ ), chlorophylls $\left(R^{2}=0.9858, p<0.01\right.$, Fig. 3(B)) and SCMR $\left(R^{2}=0.8591, p<0.05\right.$, Fig. $3(\mathrm{C})$ ) at flowering stage but weaker correlations were observed for other growth stages under different water deficit levels. These relationships indicated that increasing SCMR resulted in an increase of both leaf $\mathrm{N}$ and chlorophylls, and a subsequent increase in soybean grain yield with significant differences among the different growth stages in response to different water deficit levels. Silvius et al. (1977) stated that the effects of water stress on soybean yield appeared to be related to limited availability of photosynthate and nitrogen for translocation to developing seed.
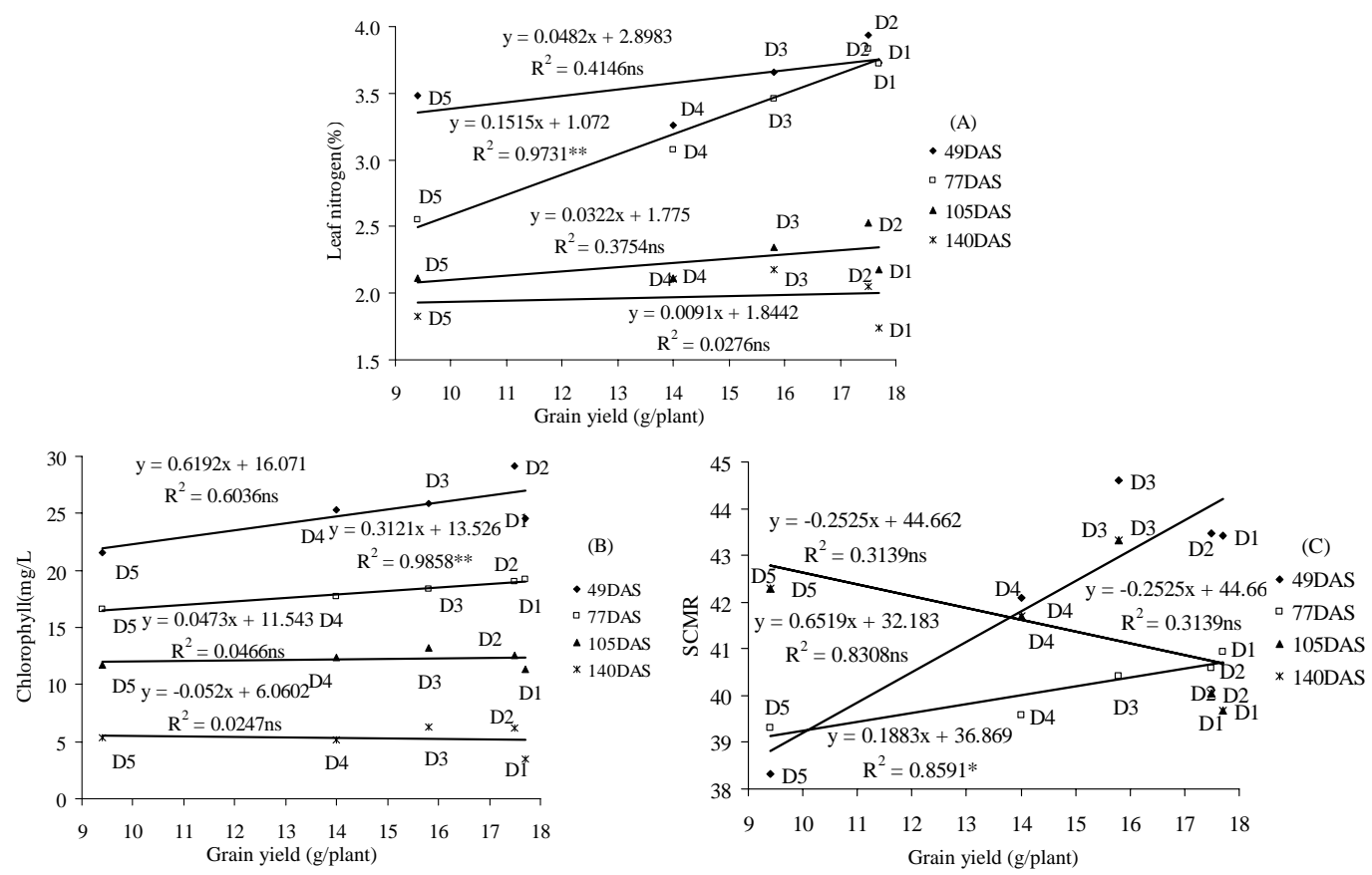

Fig. 3. Leaf nitrogen (A), chlorophylls (B) and SCMR (C) at different growth stages of soybean against grain yield under different water deficit levels. ns $=$ non significant, ${ }^{*}$ significant at $\mathrm{p}<0.05$, and $* *$ significant at $\mathrm{p}<0.01$.

Results indicate that water deficit had significant effect on the relationships among the leaf $\mathrm{N}$ accumulation, chlorophylls, SCMR and grain yield at flowering stage, because physiological maturity might reach maximum at that time. A critically important period for fixation and assimilation of nitrogen in soybean production is at the pick of the flowering stage (Sridhara et al. 1995). It appeared that SPAD chlorophyll meter reading (SCMR) and determining of leaf $\mathrm{N}$ and chlorophylls during flowering stage is the best time for the prediction of adverse water stress effects on potential yield capacity of soybean grains.

\section{References}

Boyer JS 1982. Plant productivity and environment. Science 218: 443-448.

Buttery BR and R Buzzell 1988. Soybean leaf nitrogen in relation to photosynthetic rate and yield. Can. J. Plant Sci. 68: 793-795. 
Cartelat A, ZG Cerovic, Y Goulas, S Meyer, C Lelarge, JL Prioul, A Barbittin, MH Jeuffroy, PG Gata, and I Agati 2005. Optically assessed contents of leaf polyphenolics and chlorophyll as indicator of nitrogen deficiency in wheat (Triticum aestivum L.). Field Crops Res. 91: 35-49.

Evans JR 1989. Photosynthesis and nitrogen relationships in leaves of C3 plants. Oecologia 78: 9-19.

Fritschi FB and JD Ray 2007. Soybean leaf nitrogen, chlorophyll content, and chlorophyll $a / b$ ratio. Photosynthetica 45(1): 92-98.

Huk R, U Rinderle-Zimmer, HK Lichtenthaler and L Natr 1993. Chlorophyll a fluorescence signatures of nitrogen deficient barley leaves. Photosynthetica 28: 151-159.

Lichtenthaler HK, C Buschmann, M Doll, HJ Fietz, T Bach, U Kozel, D Meier and U Rahmsdorf 1981. Photosynthetic activity, chloroplast ultrastructure and leaf characteristics of high-light and low-light plants and of sun and shade leaves. Photosynth. Res. 2: 115-141.

Marquard RD and JL Tipton 1987. Relationship between extractable chlorophyll and an in situ method to estimate leaf greenness. Hort. Sci. 22: 1327.

Mauromicale G, RP Mauro, A Occhipinti and AMG Longo 2006. Effects of shading on chlorophyll content, chlorophyll fluorescence and photosynthesis of subterranean clover. J. Agron. Crop Sci. 197: 57-66.

Ommen OE, A Donnelly, S Vanhoutv, M Van Oijen, R Manderscheid 1999. Chlorophyll content of spring wheat leaves grown under elevated $\mathrm{CO}_{2}$ concentrations and other environmental stress within the ESPACE-wheat project. Eur. J. Agron. 10: 97-103.

Sandoval-Villa M, CW Wood and EA Guertal 2002. Tomato leaf chlorophyll meter readings as affected by variety, nitrogen form and night time nutrient solution strength. J. Plant Nutr. 25: 2129-2142.

Sheshshayee MS, H Bindumadhava, NR Rachaputi, TG Prasad, M Udayakumar, GC Wright and SN Nigam 2006. Leaf chlorophyll concentration relates to transpiration efficiency in peanut. Ann. Appl. Biol. 148: 7-15.

Silvius JS, RR Johnson and DB Peters 1977. Effect of water stress on carbon assimilation and distribution in soybean plants at different stages of development. Crop Sci. 17: 713-716.

Sridhara S, S Thimmegowda and TG Prasad 1995. Effect of water regimes and moisture stress at different growth stages on nodule dynamics, nitrogenase activity and nitrogen fixation in soybean (Glycine max (L.) Merrill). J. Agron. Crop Sci. 174:111-115.

(Manuscript received on 25 October, 2011; revised on 12 November, 2011) 